\section{ORIGINAL PAPER}

doi: 10.5455/medarh.2017.71.316-319

MED ARCH. 2017 OCT; 71(5): 316-319

RECEIVED: AUG 10, 2017 | ACCEPTED: 0CT 05, 2017

'Polyclinic „Dr. Nabil”, Sarajevo, Bosnia and Herzegovina

${ }^{2}$ Cardioteam Clinic, Sarajevo, Bosnia and Herzegovina

${ }^{3}$ Clinic for heart disease, blood vessels and rheumathism, University Clinical Center Sarajevo, Bosnia and Herzegovina

${ }^{4}$ Deaprtment of Pathophysiology, Medicine Faculty in Sarajevo, University of Sarajevo ${ }^{5}$ Department of Cardiology, University Clinical Center Tuzla, Bosnia and Herzegovina

Corresponding author: ass. prof. Nabil Naser, MD, PhD. Polyclinic „Dr. Nabil”, Sarajevo, Bosnia and Herzegovina. ORCID ID: http:// www.orcid.org: 0000-0002-1278-8574. E-mail:nabil@bih.net.ba (c) 2017 Nabil Naser, Mehmed Kulic, Mirza Dilic, Alen Dzubur, Azra Durak, Esad Pepic, Elnur Smajic, Zumreta Kusljugic

This is an Open Access article distributed under the terms of the Creative Commons Attribution NonCommercial License (http://creativecommons.org/ licenses/by-nc/4.0/) which permits unrestricted non-commercial use, distribution, and reproduction in any medium, provided the original work is properly cited.

\title{
The Cumulative Incidence of Stroke, Myocardial infarction, Heart Failure and Sudden Cardiac Death in Patients with Atrial Fibrillation
}

\author{
Nabil Naser ${ }^{1}$, Mehmed Kulic ${ }^{2}$, Mirza Dilic ${ }^{3}$, Alen Dzubur ${ }^{3}$, Azra Durak ${ }^{3}$, Esad \\ Pepic $^{4}$, Elnur Smajic ${ }^{5}$, Zumreta Kusljugic ${ }^{5}$
}

\begin{abstract}
Introduction: Atrial fibrillation represents the most common cardiac arrhythmia in clinical practice. By year 2030, 14-17 million AF patients are anticipated in the European Union. Atrial fibrillation remains one of the major causes of stroke, heart failure, sudden death all over the world. Research Objectives: The objective of our study is to determine the cardiac and cerebrovascular events (myocardial infarction, heart failure, stroke, sudden cardiac death) and their cumulative incidence during 11 years follow up period. Patients and methods: This study includes 2352 ambulant and hospitalized patients with atrial fibrillation (AF) who were enrolled during the follow up period. All patients underwent clinical evaluation in order to determine cardiac and cerebrovascular events (myocardial infarction, heart failure, stroke, sudden cardiac death) and their cumulative incidence. Results: The results of cumulative incidence for sudden cardiac death was $1.71 \%$, for stroke $2.56 \%$, for myocardial infarction $1.20 \%$ and for heart failure was $5.73 \%$. In our study the age-adjusted incidence and prevalence of AF are slightly lower in women. The study shows that the risk of death is higher in females than in males with AF. Conclusion: Despite good progress in the management of patients with atrial fibrillation (AF), this arrhythmia remains one of the major causes of stroke, heart failure, sudden death. Effective treatment of patients with atrial fibrillation includes not only rate control, rhythm control, and prevention of stroke, but also management of cardiovascular risk factors and concomitant diseases.
\end{abstract}

Keywords: Atrial fibrillation, Stroke, Myocardial infarction, Heart failure, Sudden death.

\section{INTRODUCTION}

Atrial fibrillation represents the most common cardiac arrhythmia in clinical practice. Patients with AF have significantly poorer quality of life than healthy controls. Despite good progress in the management of patients with AF, this arrhythmia remains one of the major causes of stroke, heart failure, sudden death, and cardiovascular morbidity all over the world. In 2010, the estimated numbers of men and women with AF worldwide were 20.9 million and 12.6 million, respectively. By year 2030, 14-17 million AF patients are anticipated in the European Union, with $120,000-215,000$ newly diagnosed patients annually.

\section{REASEARCH OBJECTIVES}

The first objective of our study is to determine the cardiac and cerebrovascular events (myocardial infarction, heart failure, stroke, sudden cardiac death) and their cumulative incidence during median follow up period $9.7 \pm 1.8$ years (September 2006 - September, 2016).

\section{PATIENTS AND METHODS}

This study includes 2352 ambulant and hospitalized patients with atrial fibrillation (AF) who were enrolled during median $9.7 \pm 1.8$ follow up period (September 2006 until September, 2016). A complete medical history was taken and all patients underwent clinical evaluation which includes thorough assessment for concomitant conditions, establishing the AF pattern, estimation of stroke, myocardial infarction, heart failure and sudden death risk. The AF was documented by 12-lead ECG or ambulatory ECG Holter recording. All patients were subjected to echocardiography to assess left atrial diameter and volume. In this study the following types of $\mathrm{AF}$ were included: newly diagnosed, paroxysmal, persistent and permanent AF. During 
the follow up period, cardiac and cerebrovascular events were evaluated (myocardial infarction, heart failure, stroke, sudden death) and their cumulative incidence.

\section{RESULTS}

During the follow up period, we analyzed and follow up 2352 patients with ECG documented different type of atrial fibrillation in order to evaluate the cumulative incidence of sudden death, stroke, myocardial infarction and heart failure. The demographic data, risk factors, clinical and comorbidity characteristics for all patients are shown on Table 1 . The cumulative incidence of sudden death, stroke, myocardial infarction and heart failure is shown on Figure 1.

In our study among 2352 patients, AF was reported to be first detected in 352, paroxysmal in 194, persistent in 728, and permanent in 1078 patients. Concomitant diseases were present in $84 \%$ of all patients. Oral anticoagulation with $\mathrm{VKA}_{\mathrm{s}}$ was prescribed in 35\% and $\mathrm{NOAC}_{\mathrm{s}}$ in $44 \%$ of patients, respectively. A rhythm control strategy was applied in $63 \%$ of currently symptomatic patients and in $47 \%$ of patients who never experienced symptoms according to the ESC guidelines.

In our study the age-adjusted incidence and prevalence of AF are slightly lower in women. The study shows that the risk of death is higher in females than that in males with AF, the risk of stroke is higher also in women with AF. The risk of myocardial infarction in our study was higher in men, the study shows that the risk of heart failure was almost same in both gender.

During median follow up period $9.7 \pm 1.8$ years, the cumulative incidence for sudden cardiac death was $1.71 \%$, for stroke $2.56 \%$, for myocardial infarction 1.20 and for heart failure was $5.73 \%$. Our study shows that the majority of patients with atrial fibrillation have mild to moderate enlargement of left atrium, more than half of patients have mildly-moderately reduced LV EF.

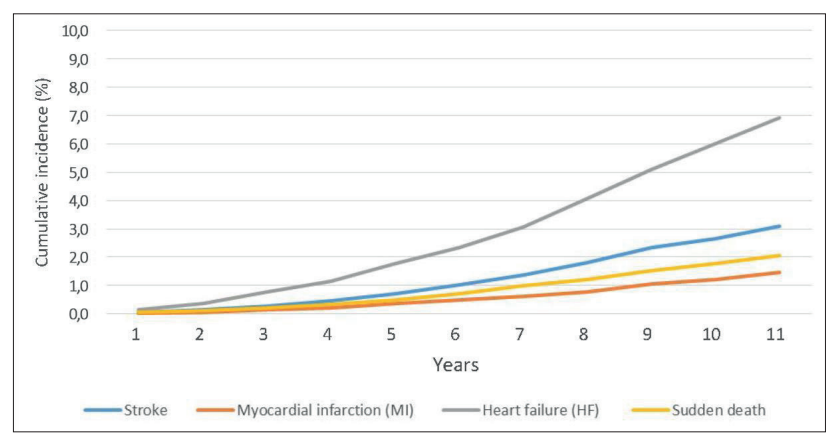

Figure 1. The cumulative incidence of stroke, MI, HF and SD during the follow up period

\section{DISCUSSION}

Atrial fibrillation is the most common arrhythmia in the general population, with a prevalence of $1.5-2 \%$, which increases with age. In addition, it occurs more frequently in males, with a male to female ratio of 1.2:1. In 2010, the estimated numbers of men and women with AF worldwide were 20.9 million and 12.6 million, respectively, with higher incidence and prevalence rates in developed countries. One in four middle-aged adults in Europe and the US will develop AF. By 2030, 14-17 million AF patients are anticipated in the European Union, with 120000 - 215000 newly diagnosed patients per year. Given that AF is associated with significant morbidity and mortality, this increasing number of individuals with AF will have major public health implications (1-7).

In our study, the mean age of the patients was $68 \pm 13$ years, the males represent $52 \%$ of patients with AF. The published studies also have reported a predominance of males (generally around 60\%), the mean age of the patients in most reports is between 65 and 70 years, which is comparable to the mean age of our population $(8,9)$.

In our study, family history of CAD was present in $31 \%$ of patients with AF, [HR 1.543 (CI 1.359 - 1.746)], also CAD was found in $39 \%$ of patients [HR 0.916 (CI $0.763-1.069)$ ], which is in consistent with the results of published studies. Violi F et al. In their investigation they searched MEDLINE via PubMed and Cochrane database between 1965 and 2015. All observational clinical studies and interventional trials reporting 1-year incidence 
of MI in AF were included. The main conclusion was that AF patients had a significant residual risk of MI despite anticoagulant treatment (10).

Echocardiography provides vital information about cardiac chambers and function, complications, and prognosis in patients with AF. This information may be helpful in determining the conditions associated with AF, the risk for recurrent AF following cardioversion, and the hemodynamic benefit of maintaining sinus rhythm, also identification of patients at increased risk for thromboembolic complications of AF before cardioversion and in patients with chronic AF (11-15).

In the reviewed literature, the prescription of oral anticoagulation on hospital discharge was also lower in patients with paroxysmal vs. permanent AF (51 vs. 80\%, 55 vs. $74 \%, 78$ vs. $91 \%)$. In a Swiss registry of outpatients with AF seen by cardiologists, prescription of anticoagulants reached $88 \%$ in patients with a CHADS 2 score $\geq$ 1 . However, $57 \%$ of the patients with a score of zero also received anticoagulants (16-19).

During median follow up period $9.7 \pm 1.8$ years, the cumulative incidence for sudden cardiac death was $1.71 \%$, for stroke $2.56 \%$, for myocardial infarction 1.20 and for heart failure was $5.73 \%$. The cumulative incidences of stroke, myocardial infarction, heart failure and sudden cardiac deathare similar to those in published studies and meta-analysis. The published studies shows the following cumulative incidence for stroke 5-7.5\%, MI $0.4-2.5 \%$, heart failure 6-35\% $(1-4,7,8)$.

Krijthe BP et al. had estimated that from 2010 to 2060, the number of adults 55 years and over with AF in the European Union will more than double. As AF is associated with significant morbidities and mortality, this increasing number of individuals with AF may have major public health implications (20). In other systematic review by Wolowacz S.E. et al. for the economic burden of AF, hospitalizations consistently represented the major cost driver. In the USA, AF hospitalizations alone cost $\$ 6.65$ billion in 2005. Costs and hospitalizations attributable to AF have increased markedly over recent decades and are expected to increase in future due to ageing populations (21).

\section{CONCLUSION}

Despite good progress in the management of patients with atrial fibrillation (AF), this arrhythmia remains one of the major causes of stroke, heart failure, sudden death, and cardiovascular morbidity in the world. AF is associated with a 4-fold increase in the risk of stroke, 3-fold increase in the risk of heart failure, and 1.5-1.9 increased risk of death. Death. AF is known to have a significant impact on healthcare costs, with the major cost drivers being hospitalizations, stroke, and loss of productivity. Atrial fibrillation should be considered as a manifestation of hypertensive heart disease. Effective treatment of patients with atrial fibrillation includes not only rate control, rhythm control, and prevention of stroke, but also management of cardiovascular risk factors and concomitant diseases.
- Conflict of interest: none declared.

- Authors contributions: All authors participated in every step of research and gave final approval of the version to be submitted.

\section{REFERENCES}

1. Masic I, Dilic M, Raljevic E, Vulic D, Mott D. Trends in Cardiovascular Diseases in Bosnia and Herzegovina and Perspectives with HeartScore Programme. Med Arh. 2010; 64(5): 260-3.

2. Chugh SS, Havmoeller R, Narayanan K, Singh D, Rienstra M, Benjamin EJ, Gillum RF, Kim YH, McAnulty JH Jr, Zheng ZJ, Forouzanfar MH, Naghavi M, Mensah GA, Ezzati M, Murray CJ. Worldwide epidemiology of atrial fibrillation: a Global Burden of Disease 2010 Study. Circulation. 2014; 129: 837-47.

3. Kirchhof P, Benussi S, Kotecha D, Ahlsson A, Atar D, et al. 2016 ESC Guidelines for the management of atrial fibrillation developed in collaboration with EACTS. European Heart Journal. 2016; 37: 2893-2962.

4. Townsend N, Wilson L, Bhatnagar P, Wickramasinghe K, Rayner M, Nichols M. Cardiovascular disease in Europe: epidemiological update 2016. European Heart Journal 2016; 37: 3232-45.

5. Nguyen TN, Hilmer SN, Cumming RG. Review of epidemiology and management of atrial fibrillation in developing countries. Int J Cardiol. 2013; 167: 2412-20.

6. Zoni-Berisso M, Lercari F, Carazza T, Domenicucci S. Epidemiology of atrial fibrillation: European perspective. Clin Epidemiol. 2014; 6: 213-20.

7. Vermond RA, Geelhoed B, Verweij N, Tieleman RG, Van der Harst P, Hillege HL, Van Gilst WH, Van Gelder IC, Rienstra $M$. Incidence of atrial fibrillation and relationship with cardiovascular events, heart failure, and mortality: a community-based study from the Netherlands. J Am Coll Cardiol. 2015 Sep 1; 66(9): 1000-7.

8. Le Heuzey JY, Breithardt G, Camm J, Crijns H, Dorian P, Kowey PR. The Record AF study: design, baseline data, and profile of patients according to chosen treatment strategy for atrial fibrillation. Am J Cardiol. 2010; 105(5): 687-93.

9. Zubaid M, Rashed WA, Alsheikh-Ali AA, Almahmeed W, Shehab A, Sulaiman K, et al. Gulf Survey of Atrial Fibrillation Events (Gulf SAFE): design and baseline characteristics of patients with atrial fibrillation in the Arab Middle East. Circ Cardiovasc Qual Outcomes. 2011; 4(4): 477-82.

10. Violi F, Soliman Z. E, Pignatelli P, Pastori D. Atrial Fibrillation and Myocardial Infarction: A Systematic Review and Appraisal of Pathophysiologic Mechanisms. Journal of the American Heart Association. 2016; 5: e003347.

11. Ellinor PT, Lunetta KL, Albert CM, Glazer NL, Ritchie MD, Smith AV, Arking DE. et al. Meta-analysis identifies six new susceptibility loci for atrial fibrillation. Nat Genet. 2012; 44: 670-75.

12. Odutayo A, Wong CX, Hsiao AJ, Hopewell S, Altman DG, Emdin CA. Atrial fibrillation and risks of cardiovascular disease, renal disease, and death: systematic review and meta-analysis. BMJ. 2016 6; 354: i4482.

13. Tae-Seok Kim, Ho-Joong Youn. Role of Echocardiography in Atrial Fibrillation. J Cardiovasc Ultrasound. 2011; 19(2): 51-61.

14. Fuster V, Rydén LE, Cannom DS, et al. 2011 ACCF/AHA/HRS focused updates incorporated into the ACC/AHA/ESC 2006 guidelines for the management of patients with atrial fibrillation: a report of the American College of Cardiology Foun- 
dation/American Heart Association Task Force on practice guidelines. Circulation. 2011; 123: e269.

15. Nieuwlaat R, Capucci A, Camm AJ, Olsson SB, Andresen D, Davies DW, et al. European Heart Survey Investigators Atrial fibrillation management: a prospective survey in ESC member countries: the Euro Heart Survey on Atrial Fibrillation. Eur Heart J. 2005; 26(22): 2422-34.

16. Lip GY, Laroche C, Ioachim PM, Rasmussen LH, Vitali-Serdoz L, Petrescu L, et al. Prognosis and treatment of atrial fibrillation patients by European cardiologists: one year follow-up of the EURObservational Research Programme-Atrial Fibrillation General Registry Pilot Phase (EORP-AF Pilot registry). Eur Heart J. 2014; 1435(47): 3365-76.

17. Medjedovic S, Deljo D, Sukalo A,Masic I. Clinical-epidemiological study on stroke presence in the population of Herzegovina -Neretva canton influenced by investigated risk factors. Mater Sociomed. 2015 Oct; 27(5): 314-7.

18. Dilic M, Begic A, Sabanovic-Bajramovic N, Bico A, Terzic O. Antithrombotic therapy for the secondary prevention of ischemic stroke related to atrial fibrillation: $\mathrm{ESC} / \mathrm{ACC} / \mathrm{ACCP}$ Guidelines. Cardiologia Croatica. 2013; 8(9): 299.

19. Kirchhof P, Ammentorp B, Darius H, De Caterina R, Le Heuzey JY, Schilling RJ, Schmitt J, Zamorano JL. Management of atrial fibrillation in seven European countries after the publication of the 2010 ESC Guidelines on atrial fibrillation: pri- mary results of the PREvention of thromboemolic events European Registry in Atrial Fibrillation (PREFER in AF). Europace. 2014; 16:6-14.

20. Krijthe BP, Kunst A, Benjamin EJ, et al. Projections on the number of individuals with atrial fibrillation in the European Union, from 2000 to 2060. Eur Heart J. 2013; 34: 2746-51.

21. Wolowacz SE, Samuel M, Brennan VK, Jasso-Mosqueda JG, Van Gelder IC. The cost of illness of atrial fibrillation: a systematic review of the recent literature. Europace. 2011; 3: 1375-85.

22. January CT, Wann LS, Alpert JS, Calkins H, Cigarroa JE, Cleveland JC Jr, Conti JB, Ellinor PT, Ezekowitz MD, Field ME, Murray KT, Sacco RL, Stevenson WG, Tchou PJ, Tracy CM, Yancy CW, ACC/AHA Task Force Members. 2014 AHA/ ACC/HRS guideline for the management of patients with atrial fibrillation: executive summary: a report of the American College of Cardiology/American Heart Association Task Force on practice guidelines and the Heart Rhythm Society. Circulation. 2014; 130(23): 2071-104.

23. Naser N, Dzubur A,Durak A,Kulic M,Naser NU.. Blood Pressure Control in Hypertensive Patients, Cardiovascular Risk Profile and the Prevalence of Masked Uncontrolled Hypertension (MUCH). Med Arch. 2016 Jul 27; 70(4): 274-9.

24. Masic I, Rahimic M, Dilic M, Kadribasic R, Toromanovic S, Socio-medical Characteristics of Coronary Disease in Bosnia and Herzegovina and the World. Mater Sociomed. 2011; 23(3): 171-83. 